\title{
Residual stresses analysis of ND-YAG laser welded joints
}

\author{
J.M. Costa ${ }^{\text {a, } *}$, J.T.B. Pires ${ }^{b}$, F. Antunes ${ }^{\text {a }}$, J.P. Nobre ${ }^{\text {a }}$, L.P. Borrego ${ }^{c}$ \\ ${ }^{a}$ CEMUC, Department of Mechanical Engineering, University of Coimbra- Polo II, Pinhal de Marrocos, 3030-788 Coimbra, Portugal \\ ${ }^{\mathrm{b}}$ Department of Mechanical Engineering, Polytechnic Institute of Castelo Branco, Avenida do Empresário, 6000-767 Castelo Branco, Portugal \\ ${ }^{\mathrm{c}}$ CEMUC, Department of Mechanical Engineering, Institute Superior de Engenharia de Coimbra, Rua Pedro Nunes, Quinta da Nora, 3030-199 Coimbra, Portugal
}

\section{A R T I C L E I N F O}

Available online $\mathrm{xxxx}$

\section{Keywords:}

Residual stresses

Laser welding

Finite element method

Hole-drilling method

X-ray diffraction

\begin{abstract}
A B S T R A C T
Laser deposit welding based on modern ND-YAG lasers is a new mould repair process with advantages relatively to the traditional methods (micro-plasma and TIG methods), namely deposition of small volumes of the filler material without distortion. Residual stresses play a major role on the fatigue and thermal-mechanical fatigue behaviour of welds. This paper presents the experimental results and numerical predictions of the residual stresses in joints manufactured with two hot-working tool steels: X.40.CrMoV.5.1 and 40.CrMnNiMo.8.6.4, in the laser-deposited layer and in the heat-affected zone. Welded specimens were prepared with U notches and filled with ND-YAG laser welding deposits. Trough-depth residual stresses evaluation after laser deposit welding were performed in order to analyse the influence of the residual stress state on fatigue behaviour of mould steels. Both X-ray diffraction $\sin ^{2} \gamma$ method (XRD) and incremental hole-drilling technique (IHD) were used in residual stress measurement. Numerical predictions of the residual stress distributions were obtained for several values of the technologic parameters, compared with experimental results and discussed based on the assumptions stated.
\end{abstract}

(c) 2008 Elsevier Ltd. All rights reserved.

\section{Introduction}

Mould producing is one of the more relevant Portuguese industries using high CAD/CAM technologies. The shape and manufacturing of tools for moulds are usually extremely exact and consequently very expensive. During moulds manufacturing, the correction of localized imperfections due to design or/and execution imperfections as well as tool marks is very frequent. Laser deposit welding, by using modern ND-YAG lasers, is a new repair process, very flexible, that have the advantage relatively to the traditional methods (Micro-plasma and TIG methods) of achieving less change of the metal composition around the repair zone. Moreover, it permits a very accurate deposition of a small volume of the filler material to the area chosen at the work-piece surface, without distortion, even in the case of a small thickness of $0.2 \mathrm{~mm}$.

In a previous work [1,2], the authors observed that welded specimens, tested at $R=0.4$, presented a similar fatigue resistance to the correspondent non-welded specimens tested for the same stress ratio and also very close to the curve obtained with welded specimens for $R=0$. Residual stresses are probably the main factor affecting this fatigue behaviour. The study presented in this paper pretends to clarify that behaviour.

Thermal cycles during welding operations always imply heterogeneous plastic deformation and microstructure modifications, leading to high residual stresses appearance. The residual stresses affect the mechanical performance of structural applications, therefore must be included in the design of components. The measurement or prediction of the residual stress state induced by the welding operations are therefore of great practical relevance.

\footnotetext{
* Corresponding author. Fax: +351 239790701.

E-mail addresses: jose.domingos@dem.uc.pt (J.M. Costa), tbom@est.ipcb.pt (J.T.B. Pires), borrego@isec.pt (L.P. Borrego).
} 
This paper presents the experimental results and numerical predictions of the residual stresses in joints manufactured with two hot-working tool steels: X.40.CrMoV.5.1 and 40.CrMnNiMo.8.6.4, in the laser-deposited layer and in the heat-affected zone. Welded specimens were prepared with U notches and filled with ND-YAG laser welding deposits. The melted material was the weaker region with lower values of hardness and higher tensile residual stresses. Through-depth residual stresses evaluation after laser deposit welding were performed in order to analyse the influence of the residual stress state on fatigue behaviour of mould steels. X-ray diffraction (XRD) was used to control the residual stress state at material's surface layer and the incremental hole-drilling (IHD) was used to control the residual stress state at deeper material's layers. Numerical predictions of the residual stress distributions were obtained for several values of the technologic parameters. Temperature dependent properties were used in these simulations. The experimental results and numerical predictions were compared and discussed based on the assumptions stated.

\section{Experimental procedure}

\subsection{Material and specimens}

Welded specimens were prepared with U notches and filled with laser welding deposits in order to simulate the repair of damaged tool surfaces. Fig. 1 illustrates the major dimensions of the samples used in the tests. The radius of the $U$ notch was $0.5 \mathrm{~mm}$ for welded specimens of H13 and P20 mould steels, respectively. Several laser-deposited layers were performed in the $U$ notched specimens.

Two base materials were used, namely hot-working tool steels X.40.CrMoV.5.1 (H13) and 40.CrMnNiMo.8.6.4 (P20). P20 steel was investigated in the as received condition with quenching and tempering heat treatment, while H13 was quenched and tempered only after machining. The chemical composition and the main mechanical properties of these alloys are shown in Tables 1 and 2, respectively. Because of its excellent combination of high toughness and resistance to thermal fatigue cracking H13 is used for more hot work tooling applications. P20 mould steel is a versatile, low-alloy tool steel that is characterized by good toughness at moderate strength levels. The X.40.CrMoV.5.1 (H13) steel is mainly used in the production of moulds for die casting processes of aluminium and magnesium alloys while the 40.CrMnNiMo.8.6.4 (P20) steel in used the production of moulds for injection and bow of plastic products. After the conclusion of the laser deposit welding operation, the specimens were grinded to obtain a homogeneous specimen thickness and to avoid the effects of stress concentration.

\subsection{Welding process}

A ND-YAG laser process was used in order to simulate the repair of damaged tool surfaces. Welding was conduced with an ND-YAG laser system, HTS 180 laser tool, using a pulsating electric current with $6 \mathrm{~Hz}$ and 8 ms of impulse time. A filler wire with $0.4 \mathrm{~mm}$ diameter was used. The power was $63 \%$ of the maximum power $(180 \mathrm{~W})$, with a laser diameter of $0.6 \mathrm{~mm}$. The chemical compositions of the filler materials are presented in Table 3 . An Air/He-mixture ( $5 \% \mathrm{He}$ ) with a flow of $0.61 / \mathrm{min}$ was used as shielding gas. Fig. 2 is a photo of the welded surface, showing the weld spots.

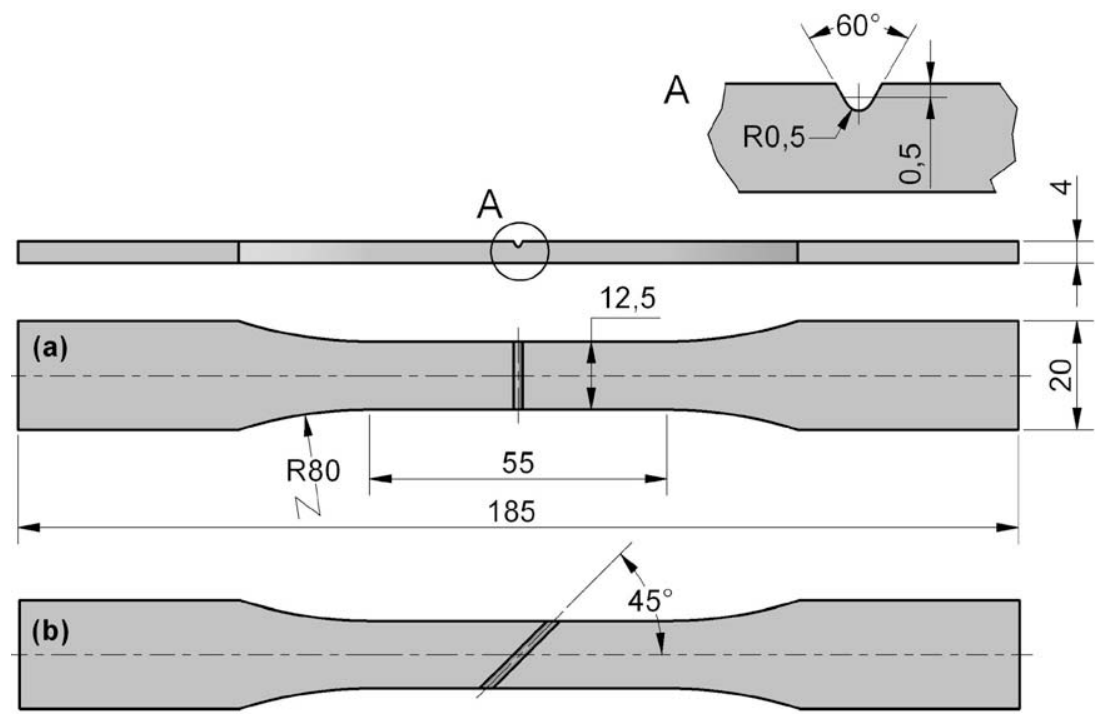

Fig. 1. Geometry of base material specimens. 
Table 1

Chemical composition of the analysed steels (weight \%).

\begin{tabular}{lllllll}
\hline Mould steel & & $\mathrm{C}$ & $\mathrm{Si}$ & $\mathrm{Mn}$ & $\mathrm{Cr}$ & $\mathrm{No}$ \\
\hline DIN & AISI & & & & \\
\hline X.40.CrMoV.5.1 & H13 & 0.39 & 1.0 & 0.4 & 5.2 & 1.3 \\
40.CrMnNiMo.8.6.4 & P20 & 0.37 & 0.3 & 1.4 & 2.0 & 0.2 \\
\hline
\end{tabular}

Table 2

Mechanical properties of the mould steels.

\begin{tabular}{|c|c|c|c|c|c|}
\hline \multicolumn{2}{|l|}{ Mould steel } & \multirow[t]{2}{*}{ Tensile strength, $\sigma_{\mathrm{UTS}}(\mathrm{MPa})$} & \multirow[t]{2}{*}{ Yield strength, $\sigma_{\mathrm{YS}}(\mathrm{MPa})$} & \multirow[t]{2}{*}{ Elongation, $\varepsilon_{\mathrm{r}}(\%)$} & \multirow[t]{2}{*}{ Hardness HV } \\
\hline DIN & AISI & & & & \\
\hline X.40.CrMoV.5.1 & H13 & 1990 & 1650 & 9 & 550 \\
\hline 40.CrMnNiMo.8.6.4 & $\mathrm{P} 20$ & 995 & 830 & 12 & 300 \\
\hline
\end{tabular}

Table 3

Chemical composition of the filler material (weight \%).

\begin{tabular}{llllllll}
\hline & C & Si & Mn & Cr & Mo & Ni & Fe \\
\hline H13 & 0.15 & 1.5 & 2 & 20 & - & - \\
P20 & 0.25 & - & 1.4 & 1.6 & 0.3 & Rest. & Rest. \\
\hline
\end{tabular}

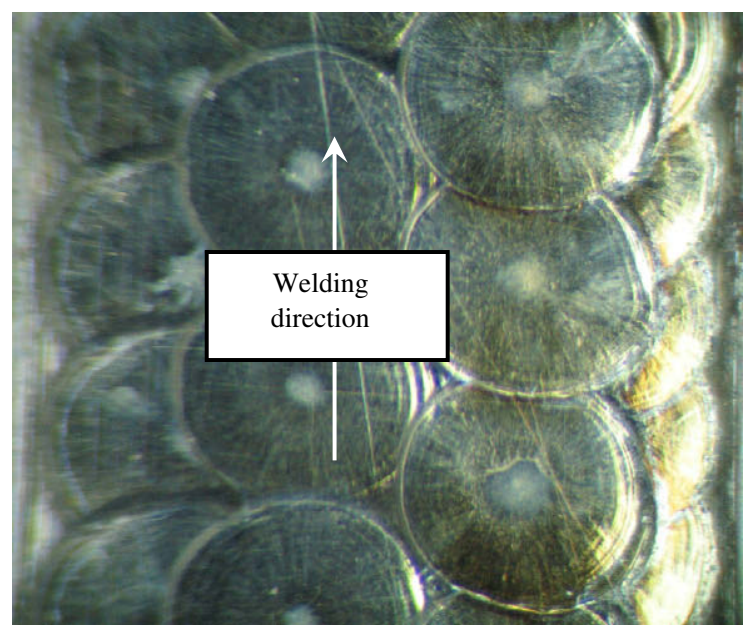

Fig. 2. Welded surface aspect showing weld spots.

In order to characterise the welded joint and the heated affected zone (HAZ) Vickers hardness profiles were obtained using a Struers Type Duramin-1 microhardness tester, with an indentation load of 2000 gf during 15 s, according to the ASTM E 348 standard [3]. The hardness profiles were obtained at the surface, along the direction normal to the laser-deposited material, close to the longitudinal centre line of welded specimens.

The measurements were performed and at each $0.25 \mathrm{~mm}$, along $5 \mathrm{~mm}$ from both sides of the laser weld centre. From H13 steel hardness profile it was concluded that the filler material has a significant lower hardness than the parent material and that the thermal effects of the welding laser process induce a slight material hardening in the HAZ and that this zone is very narrow. A minimum of $230 \mathrm{HV}$ was obtained near the middle of the weld joint and a maximum of $570 \mathrm{HV}$ in the HAZ. The P20 steel hardness profile has a very different aspect: the parent material has a hardness of about $300 \mathrm{HV}$ while the HAZ has a higher extension with a maximum of $520 \mathrm{HV}$; the filler metal has a minimum of $350 \mathrm{HV}$ at the middle of the weld joint. The chemical composition of the fillers (currently used by the moulds industry) used for welding the two steel specimens is the main cause to explain the higher hardness values found in the P20 filler metal.

\subsection{Measurement of residual stresses}

In this work the incremental hole-drilling technique (IHD) and X-ray diffraction technique (XRD) were complementarily used to determine residual stresses induced by laser deposit welding, widely used in the moulding industry for mould 
Table 4

Effective mean stress and effective stress ratio calculations for constant lives of $10^{5}$ and $10^{6}$ cycles.

\begin{tabular}{|c|c|c|c|c|c|}
\hline \multirow[t]{3}{*}{$N_{\mathrm{f}}$} & \multirow{3}{*}{$\begin{array}{l}\text { Nominal stress ratio } \\
\text { Condition } \\
\sigma_{\mathrm{YS}} \text { (addition mat.) }\end{array}$} & \multicolumn{2}{|l|}{$R=0$} & \multicolumn{2}{|l|}{$R=0,4$} \\
\hline & & Non-welded & Welded & Non-welded & Welded \\
\hline & & \multicolumn{4}{|l|}{958} \\
\hline \multirow[t]{6}{*}{100000} & $\sigma_{\mathrm{a}}(\mathrm{MPa})$ & 364.3 & 305.0 & 273.8 & 291.6 \\
\hline & $\sigma_{\mathrm{m}, \mathrm{apl}}(\mathrm{MPa})$ & 364.3 & 305.0 & 638.9 & 680.3 \\
\hline & $\sigma_{\text {max,eff }}(\mathrm{MPa})$ & 728.6 & 1000.0 & 912.7 & 1371.9 \\
\hline & $\sigma_{\text {res }}(\mathrm{MPa})$ & & 400.0 & & 400.0 \\
\hline & $\sigma_{\mathrm{m}, \mathrm{eff}}(\mathrm{MPa})$ & 364.3 & 653.0 & 638.9 & 666.4 \\
\hline & $R_{\mathrm{eff}}$ & 0.00 & 0.36 & 0.40 & 0.39 \\
\hline \multirow[t]{6}{*}{1000000} & $\sigma_{\mathrm{a}}(\mathrm{MPa})$ & 297.6 & 214.3 & 234.1 & 228.7 \\
\hline & $\sigma_{\mathrm{m}, \mathrm{apl}}(\mathrm{MPa})$ & 297.6 & 214.3 & 546.3 & 533.7 \\
\hline & $\sigma_{\text {max,eff }}(\mathrm{MPa})$ & 595.2 & 828.7 & 780.4 & 1162.4 \\
\hline & $\sigma_{\text {res }}(\mathrm{MPa})$ & & 400.0 & & 400.0 \\
\hline & $\sigma_{\mathrm{m}, \text { eff }}(\mathrm{MPa})$ & 297.6 & 743.7 & 546.3 & 729.3 \\
\hline & $R_{\text {eff }}$ & 0.00 & 0.55 & 0.40 & 0.52 \\
\hline
\end{tabular}

repairing. $\operatorname{Sin}^{2} \psi$ XRD method was used to determine the residual stress state at material surface, while IHD was applied to access the in-depth residual stress distribution. IHD method basically consists of drilling a small hole in the surface of the test material and measuring the surface strain produced by the local stress relaxation induced by the hole (typically 1$5 \mathrm{~mm}$ diameter). Among the proposed residual stress evaluation procedures based on incremental drilling, the integral method (IM) is, theoretically, the more correct [4] and, therefore, selected to be used in this work.

For XRD analysis two kinds of radiation were used. For martensitic/ferritic phases, lattice deformations of the Fe- $\alpha\{211\}$ planes were determined, on a conventional $\Psi$-diffractometer for $25 \Psi$-angles between $+39.2^{\circ}$ and $-37.6^{\circ}$, using $\mathrm{Cr} \mathrm{K} \alpha$ radiation. The residual stresses were calculated considering plan stress conditions using X-ray elastic constants (XEC) of $1 / 2$ $S_{2}=5.832 \times 10^{-6} \mathrm{MPa}^{-1}$ and $S_{1}=-1.272 \times 10^{-6} \mathrm{MPa}^{-1}$. For austenitic phases, lattice deformations of the Fe- $\gamma\{311\}$ were determined using $\mathrm{MnK} \alpha$ radiation. In this case, the residual stresses were calculated considering $1 / 2 S_{2}=7.036 \times 10^{-6} \mathrm{MPa}^{-1}$ and $S_{1}=-1.597 \times 10^{-6} \mathrm{MPa}^{-1}$. The electrolytic removal technique enabled to determine the in-depth residual stress distribution using XRD.

For the IHD technique, high speed drilling equipment (RS 200, Vishay, Inc.) was used to perform a cylindrical blind hole [5]. Surface strain relief was measured by a three-element strain gauge rosette (ASTM type A, EA-06-031RE-120, Vishay, Inc.). In depth increments of 0.02-0.08 mm were used and the surface strain relief was measured after each depth increment, to about $1 \mathrm{~mm}$ below the surface. The typical hole diameter was about $0.9 \mathrm{~mm}$. The gages were linked to a Spider8-30 measurement system (Höttinger, HBM, Gmh), using the three wires technique for a $1 / 4$ Wheatstone bridge connection. For the residual stress evaluation, a same mean Poisson coefficient of $v=0.29$ was used for both phases, while a mean Young's modulus of 210 and $196 \mathrm{GPa}$ was used, respectively, for the martensitic/ferritic steel and austenitic one. In all cases, the residual stresses were evaluated using the integral method [2]. All stress calculations were performed using the software GTR Residual Stress Group Software [6], which has been developed by our research group (CEMDRX).

\section{Experimental residual stresses}

In a previous work [1,2], the authors observed (see Figs. 3 and 4 ) that welded specimens, tested at $R=0$, present a significant lower fatigue resistance than the correspondent non-welded specimens tested for the same stress ratio. There is no stress concentration because welded specimens have a plane surface in the laser weld deposit. Also, the finishing of both welded and non-welded specimens was the same. Therefore, the decrease of the fatigue strength observed in the welded specimens was explained in terms of other factors such as filler material mechanical properties, residual stresses or welding defects. However, the welded specimens, tested at $R=0.4$, presented a similar fatigue resistance to the correspondent nonwelded specimens tested for the same stress ratio and also very close to the curve obtained with welded specimens for $R=0$. We concluded that the residual stresses were probably the main factor affecting this fatigue behaviour and that the low level of planar defects obtained with optimized welding parameters have only a small influence. The study presented in this paper pretends to clarify those fatigue results.

Fig. 5 shows the distribution of the superficial residual stresses in the P20 steel specimens, determined by XRD, along longitudinal and cross directions of the specimen. The specimens were only grinded after laser deposit welding operation Apparently the specimens have a beneficial residual stress state, since the normal residual stresses are compressive in both directions. However, this final state only occurs in the surface layer and was induced by the grinding procedure, as it will be shown in the following. It should be remembered the lower penetration depth of X-ray radiation on metallic materials, in the most usually cases. For example, on steel materials, the penetration depth of $\mathrm{Cr}$ radiation is only about $5 \mu \mathrm{m}$.

IHD was also applied to the same specimen in the centre of the weld seam, enabling to determine the in-depth residual stress distribution. Fig. 6 shows the typical radial surface strain relaxation obtained during IHD, at the centre of the weld 


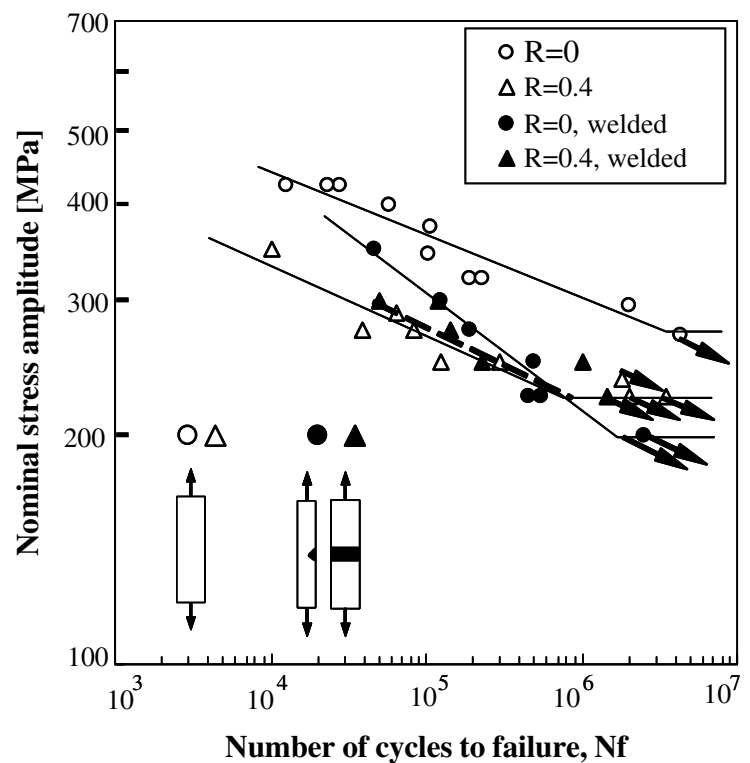

Fig. 3. S-N curves for welded and non-welded specimens. P20 steel: $R=0$ and $R=0.4$. Weld angle $=0^{\circ}$.

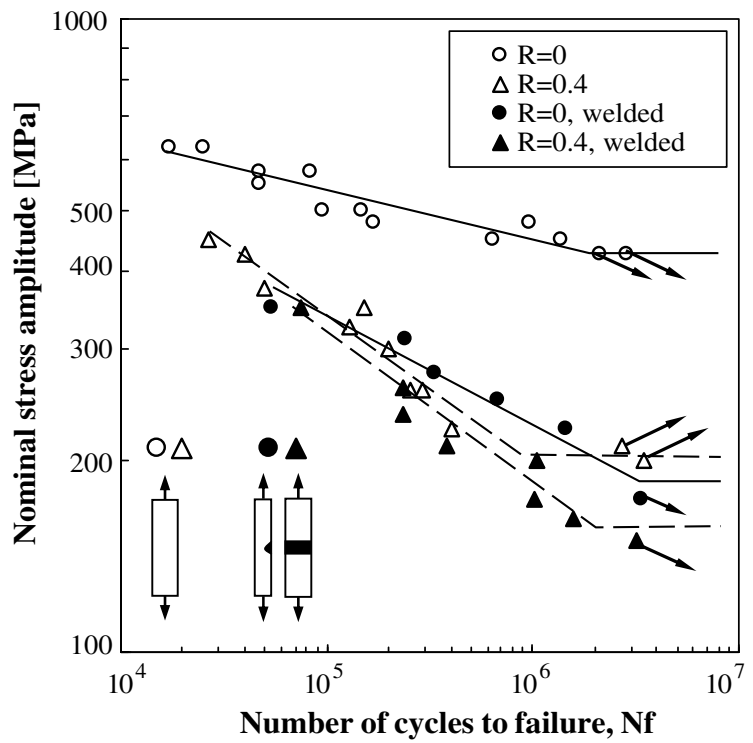

Fig. 4. S-N curves for welded and non-welded specimens. H13 steel: $R=0$ and $R=0.4$. Weld angle $=0^{\circ}$.

seam. Negative strain relaxation values will imply tensile residual stresses, apparently in contradiction to the XRD residual stress results presented in Fig. 5. Also, similar strain values were obtained in the three directions, meaning that the residual stress state is almost equi-biaxial.

Using the integral method, the in-depth residual stress distribution could be determined, from the strain-depth relaxation and the results are presented in Fig. 7. It is clear that the weld seam is subjected to high tensile residual stress state, especially if no heat treatment for stress relaxation is applied. The obtained values, at depths greater than $200 \mu \mathrm{m}$, are of the same magnitude level of material's yield stress, as Fig. 7a shows. Fatigue tests confirmed that the fatigue cracks occurred always in the weld seam and initiated always just below the surface. This behaviour is clearly justified by the in-depth residual stress profiles determined in this study. It should also be mentioned that IHD did not detect the compressive residual stresses determined by XRD at material's surface. In fact, minimum depth increment that can be used during IHD is around $20 \mu \mathrm{m}$ and the evaluation procedures can only determine a mean residual stress value for each depth increment. In addition, there is always a small influence of surface roughness on the determination of the first depth increment. In Fig. $7 \mathrm{~b}$ a similar 


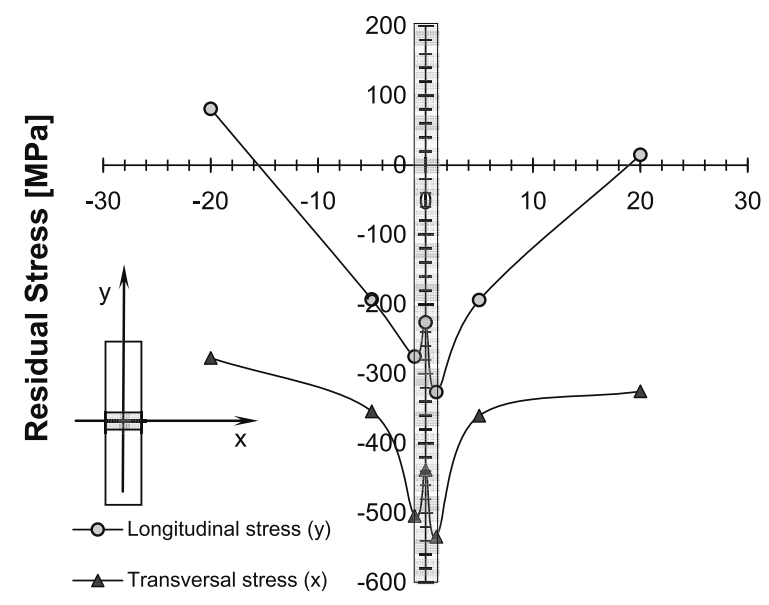

Distance to the weld seam centre [mm]

Fig. 5. Residual stress distribution at material' surface, in longitudinal and cross directions, of P20 steel specimens.

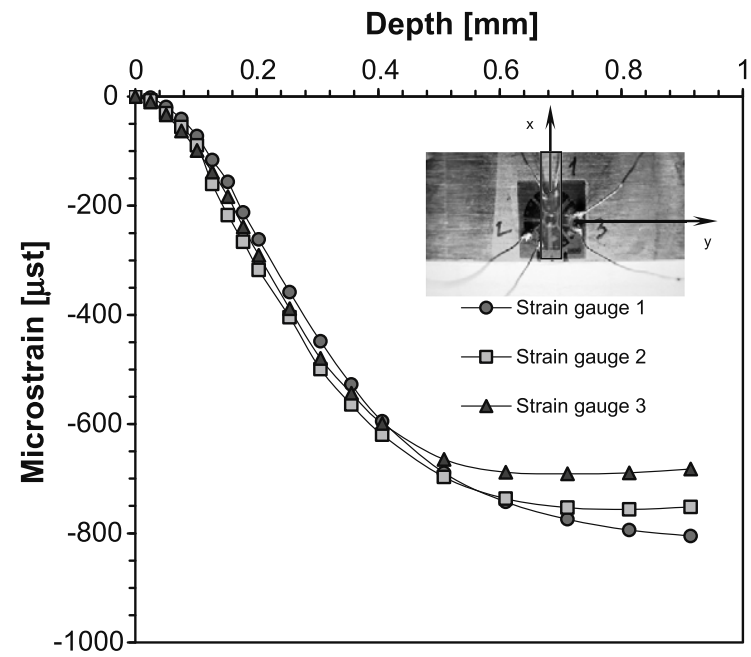

Fig. 6. In-depth evolution of radial surface strain relief during hole-drilling in P20 steel at weld seam centre, after grinding.

distribution can be observed, but the material presents lower stress values. This behaviour could be expected since, in this case, the specimen, after grinding, was subjected to heat treatment for residual stress relaxation. Residual stress in the surface near layers was not completely relieved, after the heat treatment, but it was substantially reduced. Fatigue tests performed with specimens submitted to heat treatment reveals similar fatigue lives to the non-treated specimens.

Residual stresses were also measured by the hole-drilling technique in one specimen after cyclic loading during $1.7 \times 10^{6}$ cycles. The stress range was $450 \mathrm{MPa}$ and the stress ratio was 0.4. Fig. 8 shows that residual stresses have been relieved in $y$ direction, i.e., in the same direction of the applied loading. The lower value observed was about $400 \mathrm{MPa}$. The residual stress values in the $x$-direction (not shown) remained almost unchanged.

In order to explain if residual stresses is the factor that can explain the superimposing of fatigue lives of both heat-treated and non heat-treated welded specimens tested with $R=0$ and $R=0.4$, the stress amplitude was plotted against the mean stress and the effective mean stress in the well known Haigh diagram. The effective mean stress was calculated in Table 4 with one of the following equations depending of the maximum stress value in comparison with the yield stress

$$
\begin{aligned}
& \sigma_{\mathrm{m}, \text { eff }}=\sigma_{\mathrm{m}, \text { appl }}+\sigma_{\text {res }} \quad \text { if } \sigma_{\text {max,eff }}<\sigma_{\mathrm{YS}} \\
& \sigma_{\mathrm{m}, \text { eff }}=\sigma_{\mathrm{YS}}-\sigma_{\mathrm{a}} \text { if } \sigma_{\mathrm{max}, \text { fff }}>\sigma_{\mathrm{YS}}
\end{aligned}
$$



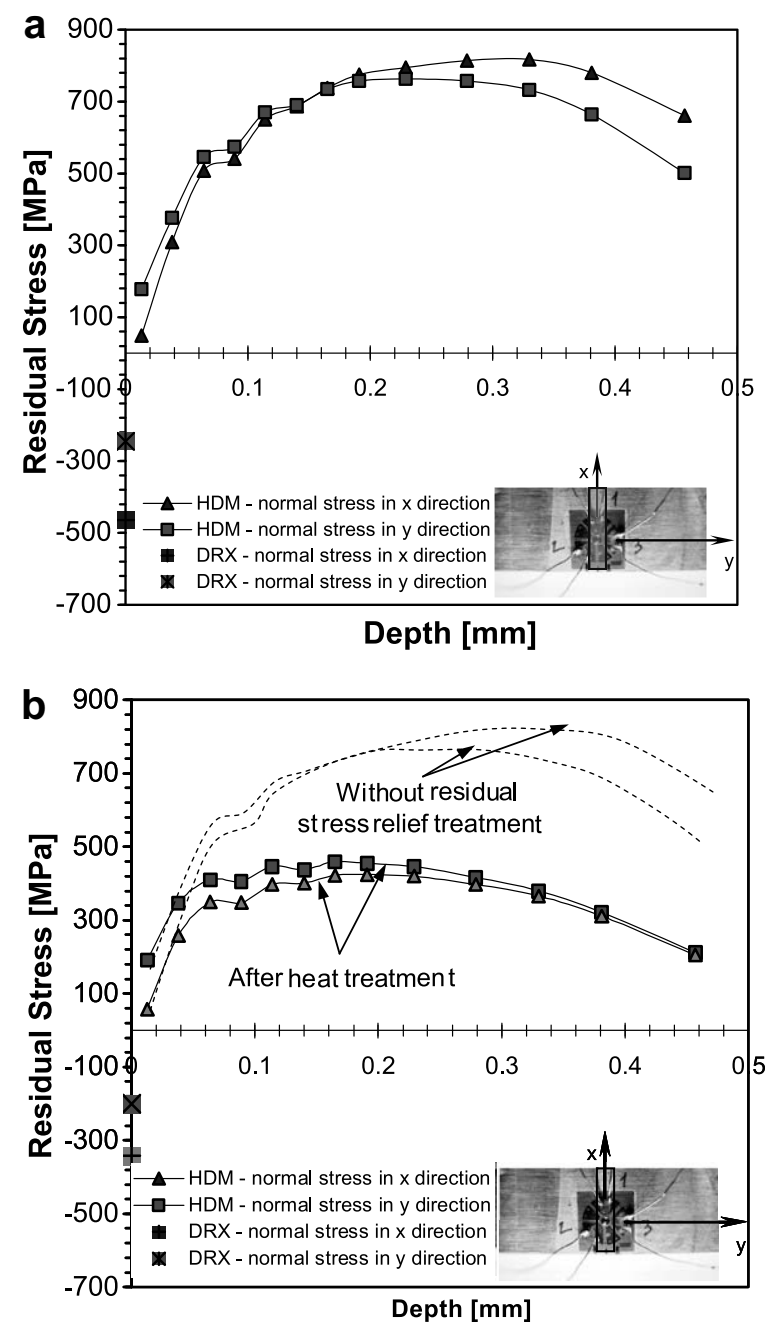

Fig. 7. In-depth distribution of residual stresses in P20 steel, at weld seam centre. (a) Without heat treatment for stress relaxation. (b) After heat treatment.

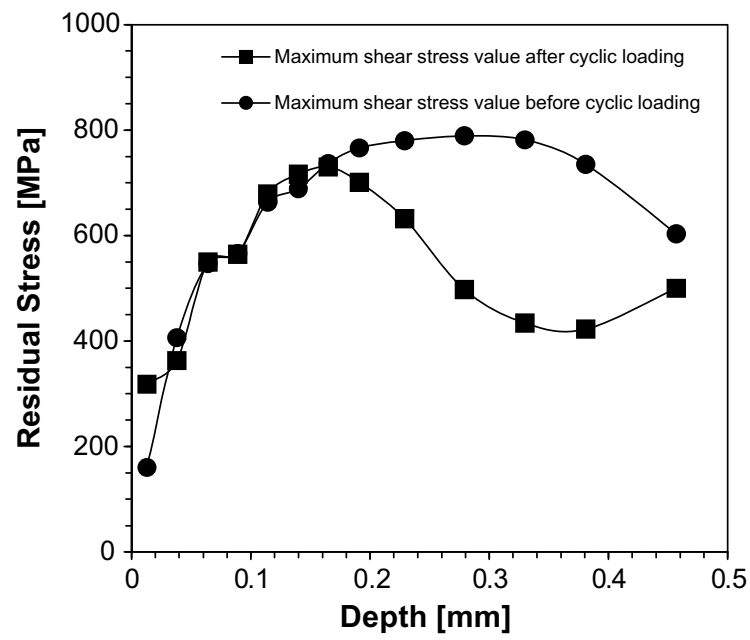

Fig. 8. Residual stresses in $y$-direction after cyclic loading during $1.7 \times 10^{6}$ cycles. Stress range of $450 \mathrm{MPa}$ and $R=0.4$. 


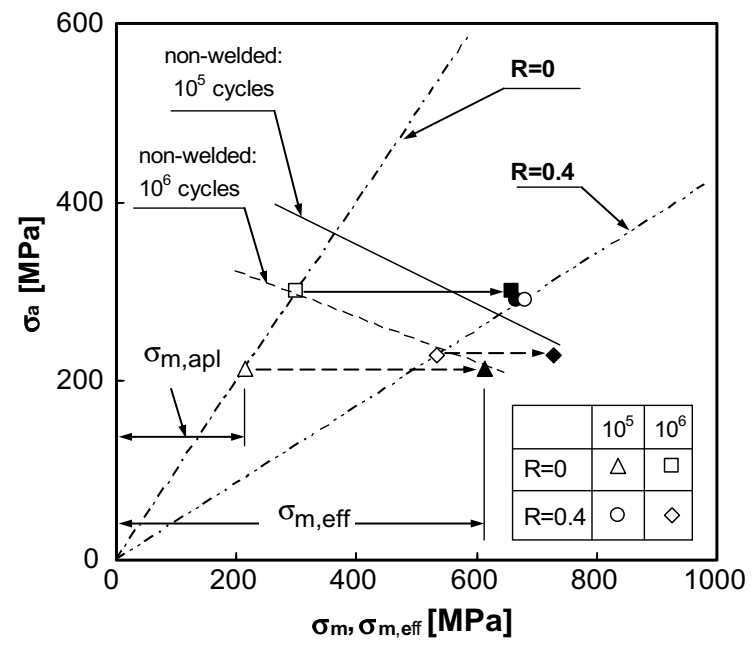

Fig. 9. Haigh diagram for P20 steel taking into account the residual stress effect.

A mean value of $400 \mathrm{MPa}$ was considered for the residual stress, measured in the heat-treated specimens and also observed after stress relaxation in the specimen tested during $1.7 \times 10^{6}$ cycles (see Fig. 8). Fig. 9 shows Haigh diagram for the P20 steel taking into account the residual stress effect. Horizontal arrows are plotted to indicate the shifting to the right of the nominal mean stresses to give the effective mean stresses, when residual stress are added to the applied cyclic stress. As a consequence, points on the figure of welded specimens tested at $R=0$ are shifted to near the $R=0.4$ curve. It can be seen that points of welded specimens tested for $R=0$ and $R=0.4$ are now close to the correspondent fatigue life curve obtained with non-welded specimens tested at $R=0.4$.

Therefore, residual stresses seems to be the main factor that explain the fatigue behaviour of the welded specimens presented in Fig. 3 where no stress ratio effect was observed in the case of welded specimens tested with both 0 and 0.4 stress ratios.

Residual stresses were also measured in the $\mathrm{H} 13$ steel specimens. However, in this case, lower residual stresses magnitude was, in general, found. These results have been confirmed by both techniques, XRD and IHD. It is certainly due to the different mechanical properties presented by both materials. Fig. 10 shows the residual stress results determined in H13 steel grinded specimens, without the application of any stress relaxation treatment.

\section{Numerical prediction}

\subsection{Numerical model}

The complexity of the physical situation raises several difficulties in the development of the model. Main challenging aspects are

- the progressive addition of material associated with the multi pass welding. The material is added progressively along the thickness;

- the complex input of energy, highly localized, and progressively along the thickness;

- the variation of main material properties with temperature; the modifications of material microstructure; the liquidsolid change, the solid phase changes.

The defined model assumes that thermal conduction is the main mechanism. Additional simplifications relatively to real situation were: the solid phase changes were not considered; the influence of deformation on the thermal dynamics was neglected.

The geometry considered in the numerical model reproduced the real geometry. However, a thickness $B=0.1 \mathrm{~mm}$ was assumed along with plane strain state. Fig. 11 illustrates the finite element mesh, composed of 1496 3D bi-linear isoparametric elements and 3200 nodes.

\subsection{Numerical results}

Fig. 12 presents preliminary results from a simplified model, which assumes that all the weld material is deposited at the same time and has an initial temperature of $700^{\circ} \mathrm{C}$. Compressive residual stresses are obtained at the weld seam centre, which are explained by material contraction due to temperature decrease. 


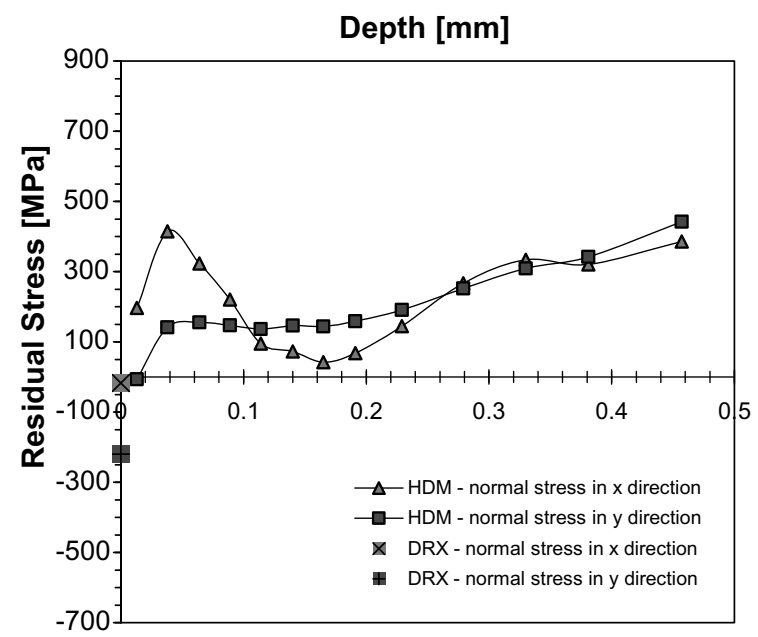

Fig. 10. Residual stress evaluation in H13 steel grinded specimens. In-depth residual stress distribution.

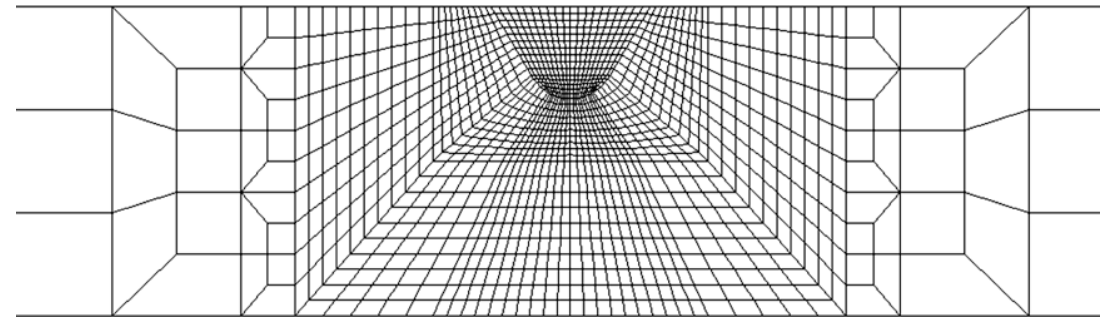

Fig. 11. Finite element mesh.

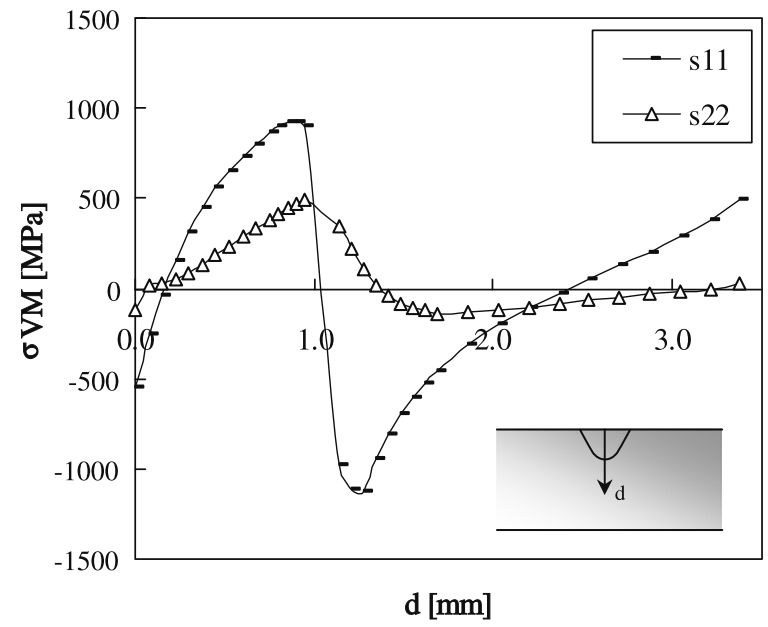

Fig. 12. In-depth residual stresses at the weld seam centre (linear elastic behaviour, $t=1 \mathrm{~s}, T_{0}=700{ }^{\circ} \mathrm{C}$, and plane strain).

The model does not reproduce real welding procedure, namely in terms of multi pass welding process, pulsed energy input mode, microstructure dependent of both mechanical and thermal properties. A more complex model is been implemented in order to consider these factors. 


\section{Conclusions}

Residual stresses induced by laser deposit welding were evaluated by incremental hole-drilling (IHD) and X-ray diffraction (XRD). Surface residual stress distribution, as well as through the thickness residual stresses at the centre of the small weld seam, were determined. Coherent and reproducible strain relaxation curves were obtained during IHD and only apparent contradictory results, determined by both techniques, were observed. In fact, high tensile residual stresses were induced by the laser deposit welding operation. However, the final grinding procedure, necessarily applied to produce the fatigue test specimens, induced a very high stress gradient at surface near layers. This strong stress gradient is not detectable by IHD, which can only determine mean stress values in $20 \mu \mathrm{m}$ minimum depth increments. The use of XRD enabled the residual stresses at material's surface to be determined, due to its small penetration depth in metallic materials. Therefore, both techniques were satisfactory used as a complement of each other.

The high tension values obtained for the residual stresses in the weld deposit, promotes an increase of the effective mean stress, which explain the fatigue results obtained by the authors in a previous work.

\section{Acknowledgements}

The authors acknowledge the financial support of FCT- Fundação para a Ciência e Tecnologia, POCI 2010 programme and FEDER - project POCI/EME/55918/2004. Anibal H. Abrantes S.A. company provides the specimens and perform the laser welds.

\section{References}

[1] Borrego LP, Pires JTB, Costa JM, Ferreira JM. Fatigue behaviour of laser repairing welded joints. Eng Fail Anal 2007;14(8):1586-93.

[2] Borrego LP, Pires JTB, Costa JDM, Ferreira JAM. Moulds repaired by laser welding. Eng Fail Anal 2009;16:596-607.

[3] American Society for Testing and Materials. Standard test method for microhardness of materials. Annual book of ASTM standards vol. 03.01 ; 2000. [ASTM E 384].

[4] Schajer G, Flaman MT, Roy G, Lu J. Hole drilling and ring core methods, In: Lu J, editor. Handbook of measurement of residual stresses, society for experimental mechanics, Fairmont Press, GA; 1996 [chapter 2].

[5] Vishay. Tech. Note TN-505; 2007. <www.vishay.com>.

[6] Nobre JP, Dias AM, Domingos AJ, Morais R, Reis MJ. A windows-based software package to evaluate residual stresses by the incremental hole-drilling technique. Comput Appl Eng Educ, doi:10.1002/cae.20225. 